\title{
A Study of Age Influence in L2 Acquisition
}

\author{
Chao Zhang \\ Qingdao University of Science and Technology \\ Qingdao 266061, China \\ E-mail: zhang_chao75@163.com
}

\begin{abstract}
The study of the second language (L2) acquisition has drawn more and more attention since the 1960s. This paper tries to explore the influence of learners' age factor as well as the other factors related to age in L2 acquisition. Considering the fact that most learners are adolescents and adults in the current foreign language education, we find it quite necessary to compare and analyze their advantages and disadvantages in foreign language learning and their learning styles, so as to improve their foreign language learning efficiency. In this paper comparisons and analyses are carried out on children, adolescents and adults to examine their characteristics respectively and their influences on language learning.
\end{abstract}

Keywords: Second language acquisition, Age, Learning strategy, Hypothesis, Teaching approach

\section{Introduction}

The problem of age is one of the factors affecting L2 acquisition. In the past few decades, the comparisons among child, adolescent and adult learners have been made by many researchers, and the different findings as well as explanations have been reported. In the investigation of the controversy over the relationship between L2 acquisition and age, the assentients and the dissidents almost constituted 50 percent respectively. Recently the scholars in the fields of linguistics, psychology and psycholinguistics have reported their study or experiment results continually, resulting in completely different points of view. So the argument for or against the critical period hypothesis has never stopped.

So there are some problems which need to be solved. Is there an optimal age, a critical period or a sensitive period? If the differences exist among children, adolescents and adults in L2 leaning, can some methods be used to narrow the gaps? How does the age factor affect the development of linguistic abilities? Are adults really inferior to children and even to adolescents? To answer these questions, many studies have been carried out to explore the relationship between the age stages and L2 acquisition by analyzing the experimental data. In essence, the whole problem bases on how the brain maturity rate affects the L2 acquisition, which involves several fields, such as neuropsychology, psycholinguistics, pedagogy and statistics.

As we know, teaching the three age groups requires different textbooks, teaching methods; environments and learning schedules owing to their different characteristics. So finding out the unique characteristic of each group by investigating and analyzing is useful in L2 teaching and learning.

\section{Comparisons among Three Age Groups}

\subsection{Traits of Childhood}

Their predominance in L2 learning is that they are in the most flexible condition. In this period their ability of language learning does not reveal any differences and their predominance appears especially in acquiring pronunciation naturally. Learning a foreign language in this stage might be strongly impressed on their brain, which can stimulate nervous function system, and the further learning can help them to form language habit and competency easily

The disadvantages in the age stage are that their long-term memory is rather bad and their first language and foreign language are easy to be mixed. Besides that, their culture and L2 culture tend to blend in a mess. They have not formed abstract logic ideation yet and have to spend more time in L1 learning than the L2 learners in other age stages. So their foreign language learning needs extraordinarily excellent conditions, such as bilingual social and living environment which can expose them to the L2 and force them to take L2 as a tool of thought, game and communication, or very good high qualified teachers and ideal teaching establishment. 
Some researchers believe children from non-English-speaking backgrounds will learn English better through structured immersion, where they have English lessons and content-based instruction in English. These programs provide more time on task in English than bilingual classes. Research, however, indicates that this increased exposure to English does not necessarily speed the acquisition of English. Over the length of the program, children in bilingual classes, with exposure to the Ll and to English, acquire English language skills equivalent to those acquired by children who have been in English-only programs (Cummins, 1981; Ramirez, Yuen \& Ramey, 1991). This would not be expected if time on task were the most important factor in language learning. Researchers also disagree with withdrawing home language support too soon and suggest that although oral communication skills in a second language may be acquired within 2 or 3 years, it may take 4 to 6 years to acquire the level of proficiency needed for understanding the language in its academic uses (Collier, 1989; Cummins, 1981). So children who are taught L2 intensively too early will damage their $\mathrm{L} 1$ acquisition.

\subsection{Traits of Adolescents}

The L2 learning predominance in this period is that their cognitive competency has grown to certain extent and their meta-language, which helps the learners to analyze or describe a language, is fairly sensitive. Therefore they are good at imitation and reminiscence. Adolescents are better than children in utilizing the strategy of language communication and they apprehend the things between the language and culture easily. Accordingly, these abilities promote the processes of L2 learning. Adolescent psychological barrier is lower than adults and they would not pay excessive attention to other people's attitude towards them. The low psychological barrier is propitious to operating inherent mechanism. Just like adults, adolescents can also take advantage of the language regulations they have learnt to monitor their outputs, but children are generally short of monitoring competency. The interjections and self-corrections that speakers make while talking show that monitoring is taking place, for the purpose of making meaning clearer. Adolescents and adults would listen to their own utterances to compare what they say with what they intend to say, and to make corrections if necessary. But children seldom act like that, they are not aware whether their utterances are appropriate or not. For these reasons, adolescents can learn L2 quicker than adults and children; meanwhile they can do better than adults and children in concrete language learning, such as syntax, listening competency and so on.

The disadvantages in adolescence are that they should study harder than children and need strong self-control in L2 learning according to their schedules. In fact it is very difficult for adolescent learners to persevere in heavy learning tasks, because they are easily affected by the other things around them. Adolescent egocentrism is a self-absorption that makes it hard for them to accept criticism and tolerate authority.

Furthermore, in this period, they have a lot of learning courses assigned by their parents and teachers, which might let them attend to one thing and lose another.

\subsection{Traits of Adulthood}

Adults' cerebra nerve network has come into being completely, and their thinking habits have become mature in this period. They can deal with complicated language form and contents easily, because their meta-language consciousnesses, common sense and literary knowledge are better than children, as Krashen (1982:21) claimed "we also use context, our knowledge of the world, our extra-linguistic competency to help us understand". So adult's predominance is especially conspicuous in reading comprehension, writing and so on. Their definite learning goals, great study motivation, rich knowledge experiences and better comprehension competency and short-term and long-term memories facilitate the process of L2 learning. Moreover, their L2 learning might be quicker than children initially through the knowledge of systematical L1 and monitor approach.

Their shortcomings are that they have not enough time to study. Their study continuity is always interrupted by social activities, which might be important for them. It is difficult for them to imitate or utter standard pronunciation and they are apparently worse than children and adolescents in getting rid of their L1 habits which are in conflict with the L2 system. So their communication ability improves rather slowly in applying knowledge of social language in conflict with their L 1 to practice.

In this part we try to find out to what extent these three groups are effected by age factors. The results indicate the relationship between their influences in the process of L2 learning and the learners' influence of age along with the other aspects in different age stages, such as motivation, attitude, opportunity and learning ability. The unique characteristic in each age stage has its advantages and disadvantages. According to Lightbown and Spada, adolescent and adult L2 learners have developed the cognitive maturity, which means the ability to engage in problem-solving, deduction, and complex memory tasks (2002: 171) and the metalinguistic awareness (2002: 177), which means the ability to treat language as an object very well, for example, being able to define a word, to say what sounds make up that word. Then they can learn grammar consciously and understand the language easily. On the other hand, a difficulty in comparing the learning ability of children, adolescents and adults is that children have the best learning conditions among the three groups: more time, attention, communicative need, opportunities for use, and so on. (William 
Littlewood 2000: 66). The characteristics concluded above can help educators find out the pertinence to teaching approaches and learning strategies in class.

\section{Teaching Approaches and Learning Strategies in Three Groups}

The differences among the three age groups are really existent and the biological L2 learning conditions are unchangeable. So the only way to improve it is teaching approaches and learning strategies. As the results listed in the previous part indicate, we can find some traits based on biology appeared in the processes of L2 acquisition. Then the teaching approaches and learning strategies should be adopted to compensate the shortcomings and taken good advantage of in three groups.

\subsection{Different Teaching Approaches in Three Groups}

As noted at the previous part, children need to be motivated by the teacher or the materials in order to learn effectively. Prizes and praises can help, but the similar extrinsic rewards are not enough. More effective on the whole are elements that contribute towards intrinsic motivation, such as interest in the learning activity. Those elements are most effective if the elements cater for the senses and activate the aspiration of children in communication. Three sources of interest for children in the class are pictures, stories and games. The picture includes all kinds of visual stimulus things, for example the photograph, disk and TV. Pictures are very dominant channel of input: and the more clearly visible, striking and colorful the better. Keller, C.M. and Keller, J. D. (1996: 126) put forward that "Linguistic forms and images are reciprocally accessible and in interactive functioning can be mutually constitutive". The teacher's own quick sketches on the blackboard and the children's own drawings are means to draw the children's attention. The stories are both visual and aural and the games are both visual and aural channels as well as activating language production. Young children love listening to the stories and older ones begin to read for themselves, which are positive language materials input. The most effective combination in teaching is pictures and stories together (Penny Ur, 2000: 289). The games convey the language information in the way of active and physical movement.

The adolescent students appear to like to feel that the teacher has authority and has them under control. Most students agree with that a good teacher treats his students with fairness and respect. The adolescents are in the sensitive period in the lifetime, so the attitude in their teacher will affect the learning attitude. The younger adolescents are more in favor of fun and less keen on hard study. Older adolescent students tend to interesting lessons and diligent working (Wragg and Wood 1984: 220-22).

Teaching adults is easier and less stressful. However, it is often directed towards

special purposes, for example business, academic study and so on. Their goals are definite and their attitude towards the lesson is positive. In the classroom, adults take more responsibility for the learning process, and rely less on the teacher's encouragement. They are in a better position to assert their right to question, criticize and generally participate actively. And they do tend to be more disciplined and conform more to the teacher's demands than younger learners. Adult learners demand final returns in terms of their own benefit in learning outcomes. Although the raising and maintaining of teaming motivation is an essential part of teaching activity with three age groups, it usually demands less investment of effort and time in adult students (Penny Ur 2000: 296).

\subsection{Different Learning Strategies Used in Three Groups}

Children employ simple learning strategies in L2 learning. Most of the children study according to their parents' and teacher's order. They may use some learning strategies intuitively and under the supervision of their parents' or teacher's instruction.

Adolescents use more complex and sophisticated learning strategies than children.

They may choose a lot of learning strategies without caring about whether it is suitable. Their strong memory in this period can get a good achievement. Adolescents lack self-discipline and can easily be distracted by other things, so their making an elaborated plan is a good method. They have enough time to communicate with teacher and classmates for solving the problems.

Most of the adult students are aware of the usage of the learning strategies and they try a lot of means and want to find good learning strategies. And their advantage is to summarize the creditable rules for themselves by their own learning experiences. The adults take advantage of L1 and social knowledge to help their learning and usually use monitor and compensation strategies in their L2 teaming processes.

"The adult learners' tendency to analyze and apply conscious thought to the learning experience may obstruct some of the natural processing mechanisms through which the new language is internalized". In this way, we may say that the adult learners rely too much on'learning', whereas children let'acquisition'takes its proper course (William Littlewood 2000:66). So we can find that adults utilize more learning strategies in L2 learning than adolescents and children.

According to what we discuss in the previous several passages, the teacher's duty is different in the three groups and the 
teaching approaches should cater for the traits of students. Teachers should manipulate a number of options according to the aim of the teaching and learning, such as different reading materials, the speed of teaching procedures, etc.

The successful language learners appear to use more strategies than the less ones.

However, all the methods have their potential strengths and weaknesses and not all learning strategies are suitable for each learner. In order to make English learners use learning strategies frequently and effectively, strategies should be integrated with the course content. Learners of different ages and stages should use different strategies. Children use strategies unconsciously and their teacher should help them form good learning habits in this period. Some adolescents might be unable to be aware of using learning strategies, and others use too many complex and sophisticated learning strategies in L2 language learning, which might not ensure to achieve high level. Adult learners prefer analytic-style strategies such as comparative and contrastive analysis, generalization rules learning, and dissecting words and phrases.

\section{Conclusion}

This paper discusses the following questions: which group is the best one in L2 acquisition? Does the age affect the process of L2 acquisition? What kind of traits exists among the age stages? Does each stage have its unique advantages and disadvantages? Based on some comparisons and analyses, several conclusions are made and some suggestions on the learning strategies are put forward.

First, the differences in the process of L2 acquisition apparently exist.

Second, the L2 development shows that although learners share the similar learning process, which is generally from simple to complex, the three groups acquire L2 by means of different learning strategies according to their age traits. Meanwhile they choose their own ways to learn L2 in conformity to their personalities, knowledge, experiences and attitudes. Besides, the successful language learners appear to use more strategies than the less ones. So a teacher's function cannot be only regarded as the impartation of knowledge in class. The real learning condition urges teachers to play their roles not only as teachers but also as guiders.

Third, age is an important factor in L2 acquisition, but its influence is not so great as to affect the achievement of a smart and diligent L2 learner. As we know, there are many factors that can work in the process of L2 learning, but every success is based on the comprehensive learning ability, which includes the learning materials they choose, the ability to change their learning strategy for better achievements. The age stages have caused different barriers to the L2 learners, but they can be overcome by different compensation means. For example, some adults' pronunciations can be improved by some compensative training. We should also know that adults' old or bad habits are very hard to get rid of. Children need their teacher's hard work, and more patience. Adolescents are potential good learners with a half mature and flexible biological foundation, which helps them acquire new knowledge quickly and easily.

Furthermore some students, who are very intelligent and can learn English very well, turn out to be laggards in English learning, and some students may be diligent but they gain average scores in their class. Meta-cognitive, cognitive, social-affective and other learning strategies should match their traits, or they would waste lots of time and gain nothing, and lose their self-confidence. In all, there are a number of factors, which can also affect L2 acquisition greatly besides the biological one.

\section{References}

Collier, V. (1989). How long: A Synthesis of Research on Academic Achievement in a Second Language. TESOL Quarterly, 23, 509-531.

Cummins, J. (1981). The Role of Primary Language Development in Promoting Educational Success for Language Minority Students. In Schooling and Language Minority Students: A Theoretical Framework. Los Angeles: California State University; Evaluation, Dissemination, and Assessment Center.

Dong, Yanping. (2003). Learning English should start in primary schools. Modern Foreign Languages, (1).

Jin, Honggang. (1997). The Study of Language Acquisition Theory. Beijing: Social Science Press of China.

Keller, C. M. and Keller, J. D. (1996). Imaging in Iron, or Thought is not Inner Speech. In Gumperz, J. J. and Levinson, S. C.(eds.) Rethinking Linguistic Relativity. Cambridge: Cambridge University Press, 115-29.

Krashen, S. (1982). Principles and Practice in Second Language Learning. Oxford: Pergamon Press.

Lightbown, P. M. and Spada, N. (2002). How Languages Are Learned. Shanghai: Shanghai Foreign Language Education Press.

Littlewood, W. (2000). Foreign and Second Language Learning. Beijing: Foreign Language Teaching and Research Press.

Ramirez, J.D., Yuen, S. D. \& Ramey, D.R. (1991). Longitudinal Study of Structured English Immersion Strategy, Early-exit and Late-exit Transitional Bilingual Education Programs for Language Minority Children. Final Report. 
Volumes 1 \& 2. San Mateo, CA: Aguirre International.

Ur, P. (2000). A Course in Language Teaching. Practice and Theory. Beijing: Foreign Language Teaching and Research Press and Cambridge University Press.

Wang, Lifei. (2000). The Theory of Modern Foreign Language Teaching. Shanghai: Shanghai Education Press.

Wragg, E. C. and Wood, E. K. (1984). Pupil Appraisals of Teaching. In Wragg, E. C.(ed.). Classroom Teaching Skills. London and Sydney: Croom Helm. 